\title{
Depletion of PI3K p85 $\alpha$ induces cell cycle arrest and apoptosis in colorectal cancer cells
}

\author{
YAN SUN, SHIYI ZHAO, HUA TIAN, XIAOYUN XIE, FAMAN XIAO, KANG LI and YUGANG SONG \\ Department of Gastroenterology, Nanfang Hospital, Southern Medical University, Guangzhou 510515, P.R. China
}

Received April 10, 2009; Accepted June 18, 2009

DOI: 10.3892/or_00000585

\begin{abstract}
Colorectal cancer is one of the most common malignancies in the world. Overactivity of phosphatidylinositol 3-kinase (PI3K) is frequently detected in colorectal carcinoma. PI3K signaling plays a pivotal role in intracellular signal transduction pathways involved in cell growth, cellular transformation, and tumorigenesis. To specifically inhibit PI3K activity in colorectal cancer cells, we constructed a siRNA against the PI $3 \mathrm{~K}$ regulatory subunit $\mathrm{p} 85 \alpha$ and transfected it into LoVo and SW480 cells. In the present study, treatment of colorectal cancer cells with PI3K p $85 \alpha$-specific siRNA inhibited cell proliferation, induced G1 phase cell cycle arrest and sensitized colorectal cancer cells to 5-FU-induced apoptosis. Furthermore, depletion of PI3K p $85 \alpha$ resulted in significant activation of three Forkhead box class $\mathrm{O}$ (FoxO) transcription factors, which inhibited the expression of cyclin D1, cdk4 and induced expression of p27/Kip1. Activation of FoxO transcription factors also increased the expression of FasL. Thus, our results indicate that siRNA-mediated gene silencing of PI3K p85 $\alpha$ may be a useful therapeutic strategy for colorectal carcinoma.
\end{abstract}

\section{Introduction}

Colorectal cancer has the third highest incidence rate of malignant tumors in the world, and its associated morbidity and mortality have increased over the years. Conventional chemotherapy regimens for the treatment of colorectal cancer have limited efficacy and are associated with significant toxicity (1). Therefore, increasing knowledge on the genetic control of cellular proliferation and modulation of signaling pathways that are aberrant in colorectal cancer have the potential to provide an effective and improved approach for its management (2).

Phosphatidylinositol 3-kinases (PI3Ks) are lipid kinases involved in tyrosine kinase receptor-mediated signal transduction and comprise a complex family with three classes,

Correspondence to: Professor Yugang Song, Department of Gastroenterology, Nanfang Hospital, Southern Medical University, Guangzhou 510515, P.R.China

E-mail:sygfimmu@yahoo.com.cn

Key words: phosphatidylinositol 3-kinase p $85 \alpha$, RNA interference, Forkhead box class O, cell cycle, apoptosis, colorectal cancer each with multiple subunits and isoforms (3). The class I PI3Ks are heterodimers composed of an $85-\mathrm{kDa}$ regulatory subunit (p85) and a 110-kDa catalytic subunit (p110). The regulatory p 85 subunit is essential for the stability of the $\mathrm{p} 110$ catalytic subunit and for its recruitment to activated growth factor receptors (4). The regulatory subunits $\mathrm{p} 85 \alpha, \mathrm{p} 50 \alpha$ and p55 $\alpha$ are encoded by the PIK3Rl gene, p $85 \alpha$ is the most abundantly expressed regulatory isoform of PI3K, and p $55 \alpha$ and $\mathrm{p} 50 \alpha$ are two additional minor alternative splicing isoforms (5). Class I PI3Ks play important roles in multiple cellular processes, such as mediating survival, apoptosis, mitogenic responses, insulin signalling and cell motility (6).

In addition to the regulation of normal cell processes, the promotion of cell survival by the activation of PI3K occurs by the inhibition of proapoptotic signals and the induction of survival signals, which contribute to the malignant transformation and tumor progression (7). Disturbances in the activation of PI3K signaling are associated with many cancers. In this regard, there is growing body of evidence to support the notion that the activation of PI3K/Akt is associated with colorectal tumors $(8,9)$, and that class I PI3Ks are expressed in colonic epithelial carcinoma cell lines (10). They are therefore attractive cancer therapeutic targets.

In a previous study (11), we demonstrated by immohistochemical analysis that the expression level of PI3K p $85 \alpha$ gradually increased when comparing normal colorectal tissue to colorectal adenoma and primary colorectal carcinoma. In this study, we investigated whether inhibition of PI3K p $85 \alpha$ by siRNA induces anti-oncogenic properties in human colorectal carcinoma cells. Here, we show that depletion of PI3K p85 $\alpha$ significantly inhibited cell proliferation, induced cell cycle arrest, and sensitized colorectal cancer cells to 5-FUinduced apoptosis. We have demonstrated that depletion of PI3K p $85 \alpha$ activated three FoxO transcription factors in colorectal cancer cells, which regulated the expression of cell cycle-associated proteins and apoptosis-associated protein. These results suggest that RNAi directed against PI3K p $85 \alpha$ might be a potential therapeutic strategy for colorectal carcinoma.

\section{Materials and methods}

Cell culture. The human colorectal cancer cell lines LoVo and SW480 were grown in RPMI-1640 supplemented with $10 \%$ fetal bovine serum under standard cell culture conditions $\left(37^{\circ} \mathrm{C}, 5 \% \mathrm{CO}_{2}\right.$ in a humidified incubator). 
siRNA and plasmid constructs. Oligonucleotides encoding 21-mer hairpin sequences were designed, and the sequences of small interfering RNA constructs targeting PI3K p $85 \alpha$ were as follows: GCUCAGUAUAAUCCCAAAUUG (sense) and CAAUUUGGGAUUAUACUGAGC (antisense). A scrambled siRNA containing the same nucleotide composition as the p $85 \alpha$ siRNA but lacking significant sequence homology to the genome was also designed as a control. The oligonucleotides were synthesized, annealed and ligated into the linearized pGPU6/Neo siRNA Expression Vector (GenePharma, China).

Selecting a population of cells that stably express siRNA. LoVo and SW480 cells were seeded in 24-well plates at a density of $5 \times 10^{4}$ per well. Twenty-four hours later, $1 \mu \mathrm{g}$ of p $85 \alpha$ siRNA plasmid or control siRNA plasmid was transfected into colorectal cancer cells using Lipofectamine 2000 (Invitrogen, USA), and cultured for an additional $24 \mathrm{~h}$ without antibiotic selection. The cells were then cultured in medium containing $1000 \mu \mathrm{g} / \mathrm{ml} \mathrm{G} 418$ (Merck, USA) until all of the cells in the non-transfected control culture were killed and antibiotic-resistant clones were formed in the transfected cells. The antibiotic-resistant cells were pooled and passaged in medium containing $500 \mu \mathrm{g} / \mathrm{ml} \mathrm{G418}$ as needed.

Cell proliferation assays. Cell proliferation was determined using the CCCK- 8 solution (Beyotime Inst Biotech, China) according to the manufacturer's instructions. Briefly, $4 \times 10^{3}$ cells/well were seeded in 96-well plates and cultured for $24,48,72$ or $96 \mathrm{~h}$. Subsequently, $10 \mu \mathrm{l} \mathrm{CCK}-8$ solution was added to each well. The cells were then incubated at $37^{\circ} \mathrm{C}$ for $2 \mathrm{~h}$ and the absorbance was finally determined at $450 \mathrm{~nm}$ using a spectrophotometer (MDC, USA).

Cell cycle analysis. The cells were trypsinized and pelleted by centrifugation. After washing the pellet with PBS, the cells were counted, and $1 \times 10^{6}$ cells were fixed in $70 \%$ ethanol at $-20^{\circ} \mathrm{C}$ for $24 \mathrm{~h}$. The fixed cells were then washed with PBS, and incubated with RNase A $(0.25 \mathrm{mg} / \mathrm{ml})$ for $30 \mathrm{~min}$ at $37^{\circ} \mathrm{C}$, and $5 \mu 1$ of propidium iodide (KeyGen, China) was then added to the cell suspension. The mixture was incubated at $\mathrm{RT}$ for $30 \mathrm{~min}$ in the dark. The suspended cells were analyzed for cell cycle using the FACSCalibur Flow Cytometer (BD, USA).

Apoptosis assays. After stable transfection, LoVo and SW480 cells were treated with 5 -FU for $48 \mathrm{~h}$ at final concentrations of 0.01 and $0.03 \mu \mathrm{mol} / \mathrm{ml}$, respectively. Cells were then trypsinized and washed twice with PBS. A total of $5 \times 10^{5}$ cells were resuspended in $500 \mu 1$ of binding buffer (KeyGen). Five microliters of Annexin V-FITC (KeyGen) was then added to the cell suspension, which was counterstained with $5 \mu \mathrm{l}$ of propidium iodide. The mixture was incubated at RT for $10 \mathrm{~min}$ in the dark, followed by apoptosis analysis using the FACSCalibur Flow Cytometer.

\section{Preparation of protein lysates}

Total protein lysate. Colorectal cancer cells stably expressing p $85 \alpha$ siRNA or control siRNA were seeded in $60-\mathrm{mm}$ dishes at a density of $1 \times 10^{5}$ cells $/ \mathrm{ml}$. They were cultured until they reached $80 \%$ confluence. After removal of the medium, the cells were washed twice with ice-cold PBS, followed by a wash with ice-cold cell lysis buffer (Beyotime Inst Biotech), which also contained freshly added $1 \mathrm{mM}$ phenylmethylsulfonyl fluoride (PMSF), $1 \mathrm{mM} \mathrm{NaSVO}$ (Sigma, USA), and $1 \mathrm{mM} \mathrm{NaF}$ (Sigma). The lysates were collected by scraping from the plates and centrifuging at $10000 \mathrm{x} \mathrm{g}$ for $5 \mathrm{~min}$ at $4^{\circ} \mathrm{C}$. The supernatant, which contained the total cell lysate, was either used immediately or stored at $-70^{\circ} \mathrm{C}$.

Nuclear and cytoplasmic protein lysates. The Nuclear and Cytoplasmic Protein Extraction Kit (Beyotime Inst Biotech) was used according to the manufacturer's instructions. Briefly, cells were washed with ice-cold PBS and pelleted by centrifugation. Three hundred microliters of ice-cold cytoplasmic lysis buffer containing freshly added $1 \mathrm{mM}$ PMSF, $1 \mathrm{mM} \mathrm{NaSVO}$ and $1 \mathrm{mM} \mathrm{NaF}$ was then added to the pellet. The pellet was incubated on ice for $15 \mathrm{~min}$ with occasional vortexing. The cell lysates were centrifuged at $15000 \times \mathrm{g}$ for $5 \mathrm{~min}$ at $4^{\circ} \mathrm{C}$, and the supernatant, which contained the cytoplasmic protein lysate, was stored at $-70^{\circ} \mathrm{C}$ until needed for Western blot analysis. The cell pellet was resuspended in ice-cold nuclear lysis buffer containing freshly added $1 \mathrm{mM}$ PMSF. The pellet was incubated on ice for $30 \mathrm{~min}$ with vigorous shaking. The cell lysates were centrifuged at $15000 \mathrm{x} \mathrm{g}$ for $10 \mathrm{~min}$ at $4^{\circ} \mathrm{C}$, and the supernatant, which contained the nuclear protein lysate, was either used immediately or stored at $-70^{\circ} \mathrm{C}$.

Western blot analysis. The protein concentration was determined using the BCA Protein Assay Kit (Beyotime Inst Biotech). Either 30 or $50 \mu \mathrm{g}$ of protein was separated by electrophoresis in $8-15 \%$ SDS-PAGE gels and transferred to PVDF membranes by semi-dry transfer. The membranes were blocked in 5\% BSA or 5\% non-fat milk in PBS-T containing $0.05 \%$ Tween-20. The membranes were then probed with the appropriate primary antibody, followed by a secondary horseradish peroxidase-conjugated antibody. The bands on the membrane specific for the protein of interest were developed with ECL solution (Pierce, USA). The following antibodies were used: primary antibodies against PI3K p85 $\alpha$, cyclin D1, cdk4 and $\beta$-actin were purchased from Santa Cruz Biotechnology (USA); primary antibodies against Akt, Phospho-Akt (Ser473), FoxO1 (FKHR), PhosphoFoxO1 (FKHR, Ser256), FoxO3a (FKHRL1), PhosphoFoxO3a (FKHRL1, Ser253), FoxO4 (AFX), Phospho-FoxO4 (AFX, Ser193), p27/Kip1, FasL and Histone H3 were purchased from Cell Signaling Technology (USA). Quantification of the protein within the bands of interest was performed using Image-pro plus 6.0 software.

Statistical analyses. All experiments were performed three separate times. Data are expressed as means \pm SD. Statistical analyses were carried out using the Student's t-test. $\mathrm{P}<0.05$ was considered as statistically significant.

\section{Results}

Suppression of PI3K p85a overexpression by RNA interference. After p $85 \alpha$ siRNA stable cell lines were established, 
A

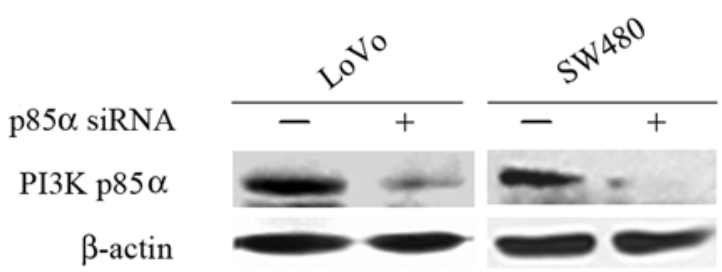

B

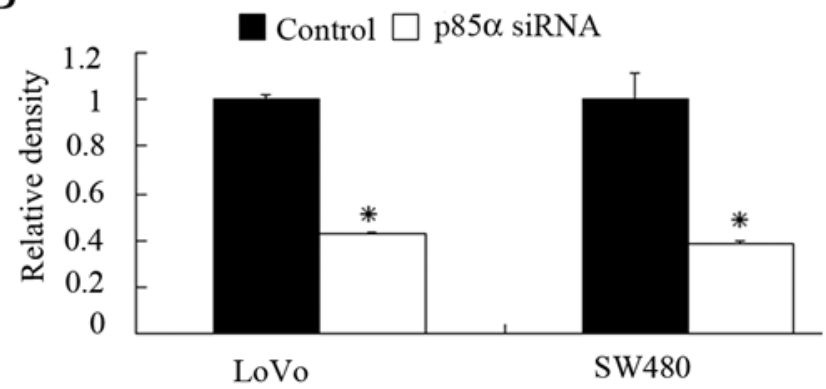

Figure 1. RNA interference effectively decreased PI3K p $85 \alpha$ protein expression. (A) Following stable transfection, whole cell extracts from LoVo and SW480 cells were analyzed by Western blotting PI3K p $85 \alpha$ protein. The corresponding $\beta$-actin levels were used as loading controls. (B) Quantification of immunoblot data from at least three experiments, the amount of each protein was calculated relative to $\beta$-actin and normalized to control cells. Columns, relative mean density; bars, $+\mathrm{SD}$. ${ }^{*} \mathrm{P}<0.05$, compared to those of control cells.

the interference effect on p85 $\alpha$ expression levels was evaluated by Western blot analysis. As shown in Fig. 1, the protein levels of PI3K p $85 \alpha$ were significantly decreased in LoVo and SW480 cells transfected with p $85 \alpha$ siRNA, compared to those of control cells. These results indicate that the siRNA could effectively suppress PI3K p85 $\alpha$ protein overexpression.

Knockdown of PI3K p85a inhibited cell proliferation. To determine the effect of $\mathrm{p} 85 \alpha$ knockdown on proliferation of colorectal cancer cells, the CCK- 8 cell proliferation assay was performed. LoVo and SW480 cells that express either p $85 \alpha$ siRNA or control siRNA were seeded and cultured until CCK-8 detection. As shown in Fig. 2, cells expressing the control siRNA grew very quickly, at a rate of 1.56- to 5.48 -fold that of the $0 \mathrm{~h}$ control cells. In contrast, cells expressing the p85 $\alpha$ siRNA exhibited a much slower proliferation rate, which was 1.13 - to 2.66 -fold that of $0 \mathrm{~h}$ control cells. These results indicate that PI3K p $85 \alpha$ plays an important role in the proliferation of colorectal cancer cells.

Depletion of PI3K p $85 \alpha$ induced cell cycle arrest. To examine if siRNA against p85 $\alpha$ has an impact on cell cycle of colorectal cancer cells, flow cytometry analyses were performed, where the results showed that depletion of $\mathrm{p} 85 \alpha$ caused a significant increase in the proportion (from 44.67 to $62.35 \%$ ) of LoVo and SW480 cells at the G1 phase (Fig. 3A and B). The observed increase in G1 cell population in LoVo and SW480 cells was accompanied by a reduction (from 40.79 to $23.89 \%$ ) of cells in the $\mathrm{S}$ phase (Fig. 3A and C). These findings suggest that depletion of PI3K p $85 \alpha$ could obviously induce colorectal cancer cell cycle arrest.
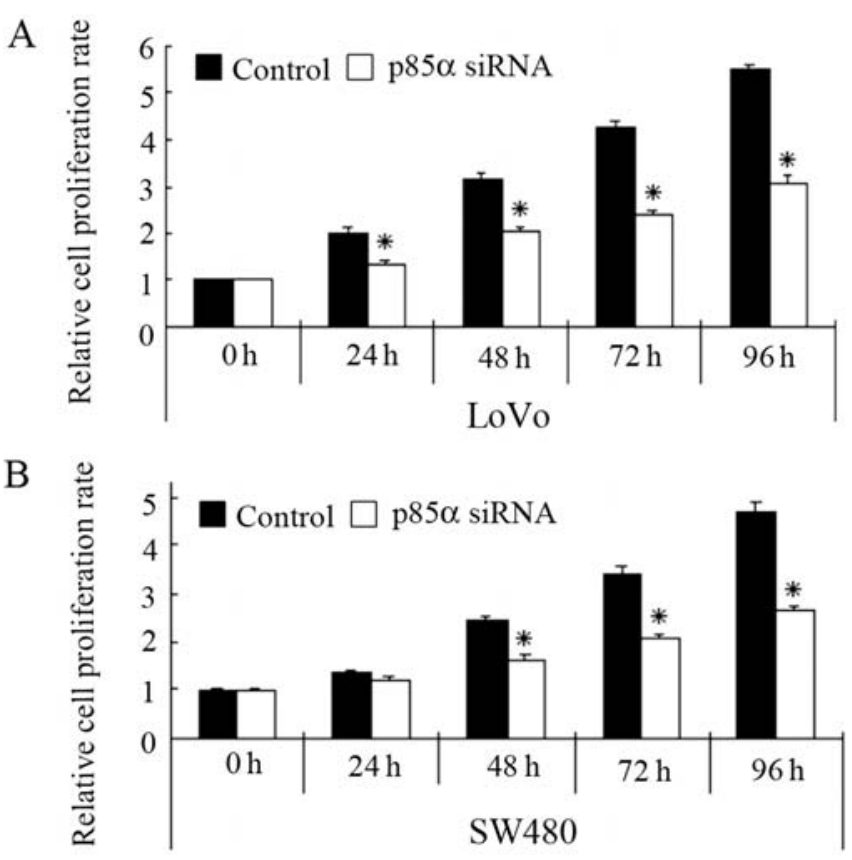

Figure 2. Down-regulation of PI3K p $85 \alpha$ inhibited the proliferation of colorectal cancer cells. LoVo (A) and SW480 (B) cells expressing p85 $\alpha$ siRNA or control siRNA were seeded and cultured. Cell proliferation was determined by the CCK- 8 assay. The absorbance of cells at $450 \mathrm{~nm}$ was normalized to that in the control at $0 \mathrm{~h}$. Proliferation assays were performed in triplicate. Columns, relative mean absorbance; bars, $+\mathrm{SD} .{ }^{*} \mathrm{P}<0.05$, compared to those of control cells.

PI3K p85a knockdown sensitized colorectal cancer cells to 5-FU-induced apoptosis. In order to evaluate the effect of p $85 \alpha$ knockdown on induction of apoptosis, LoVo and SW480 cells were treated, after stable transfection, with 5-FU at final concentrations of 0.01 and $0.03 \mu \mathrm{mol} / \mathrm{ml}$, respectively, for $48 \mathrm{~h}$. The early apoptotic rate was then assessed using the Annexin V-FITC kit by means of flow cytometry analysis. As shown in Fig. 4, the proportion of cells that were positive for Annexin V was about 7-fold higher in p85 $\alpha$ knockdown cells than in control cells. These results indicate that knockdown of PI3K p85a sensitized the colorectal cancer cells to 5-FU.

PI3K p $85 \alpha$ depletion activated FoxO transcription factors associated with regulating cell cycle-associated protein and apoptosis-associated protein expression. To further explore the mechanism that may be involved in the enhancement of cell cycle arrest and 5-FU-induced apoptosis by silencing p85 $\alpha$ in LoVo and SW480 cells, we examined the expression levels of Akt, phospho-Akt, and three Forkhead box class $\mathrm{O}$ (FoxO) transcription factors in the nucleus and cytoplasm. Our results showed that $\mathrm{p} 85 \alpha$ depletion led to a substantial reduction in the levels of Akt and phospho-Akt (Fig. 5). Consistent with this reduction in the level of phospho-Akt, Western blots revealed a significant decrease in the expression of phospho-FoxO1 (FKHR), phospho-FoxO3a (FKHRL1) and phospho-FoxO4 (AFX) in cytoplasm of p85 $\alpha$-knockdown cells (Fig. 6A and C). Prominent accumulation of FoxO1 (FKHR), FoxO3a (FKHRL1) and FoxO4 (AFX) in the nucleus 
A
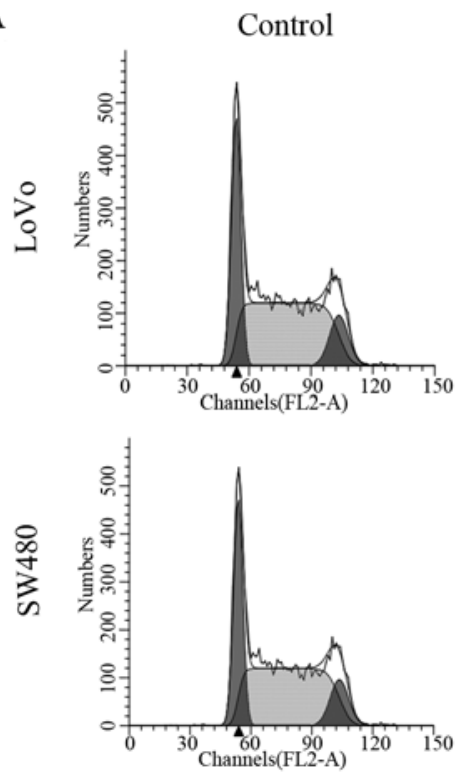

p85 $\alpha$ siRNA
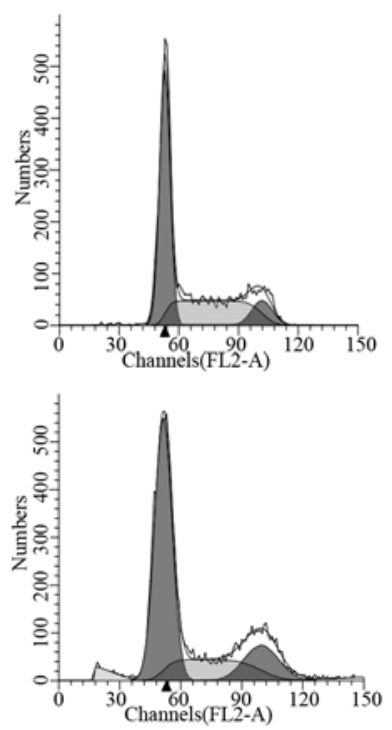

B
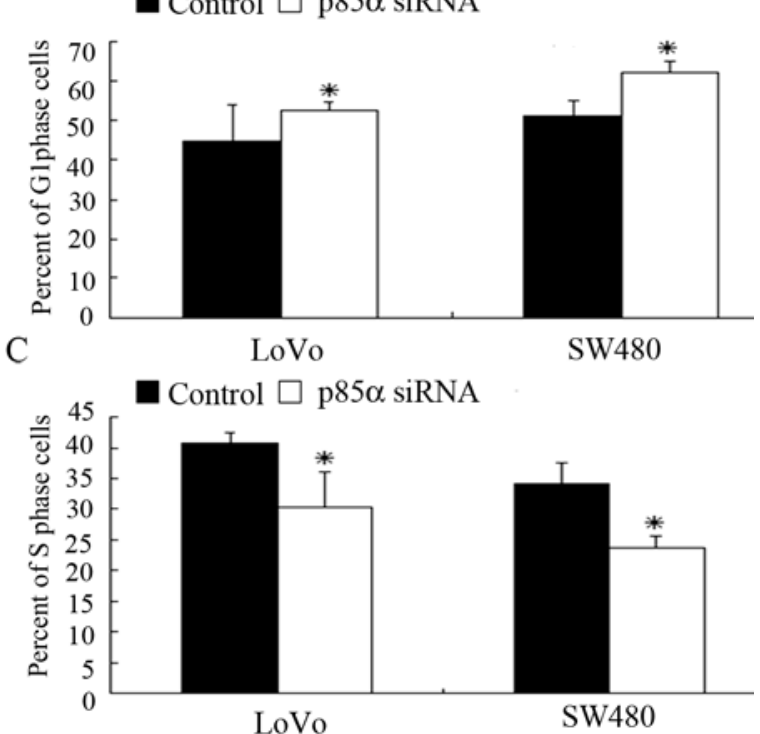

Figure 3. Depletion of PI3K p85a induced cell cycle arrest. (A) Flow cytometry analysis profiles revealed the positions of G1, S and G2/M phases of LoVo and SW480 cells after stable transfection. (B, C) Computational analysis of the cell population in G1 and S phase. Flow cytometry analyses were performed in triplicate. Columns, means; bars, $+\mathrm{SD} .{ }^{*} \mathrm{P}<0.05$, compared to those of control cells.

A
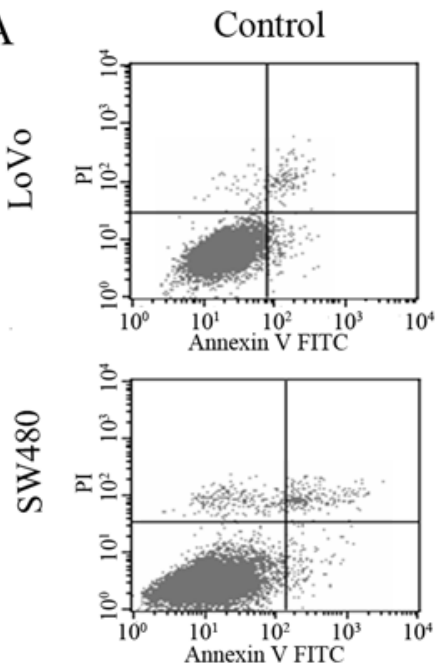

B

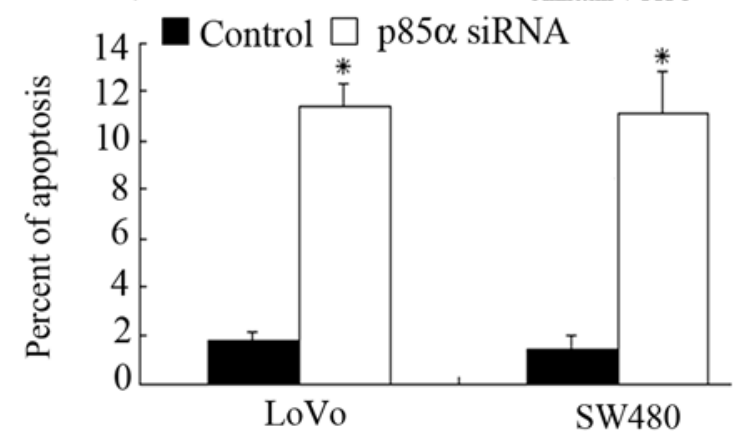

Figure 4. Depletion of PI3K p85 $\alpha$ enhanced 5-FU-induced apoptosis. (A) Following stable transfection, the extent of 5-FU-induced apoptosis was evaluated by Annexin V staining and flow cytometry analysis. (B) Computational analysis of the apoptosis rate. Flow cytometry analyses were performed in triplicate. Columns, means; bars, $+\mathrm{SD}$. ${ }^{*} \mathrm{P}<0.05$, compared to those of control cells.
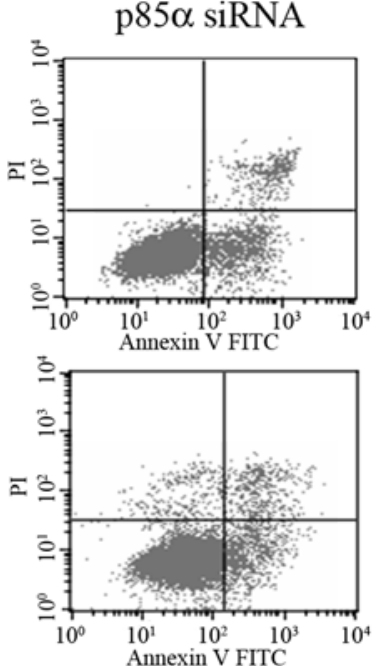

A

B

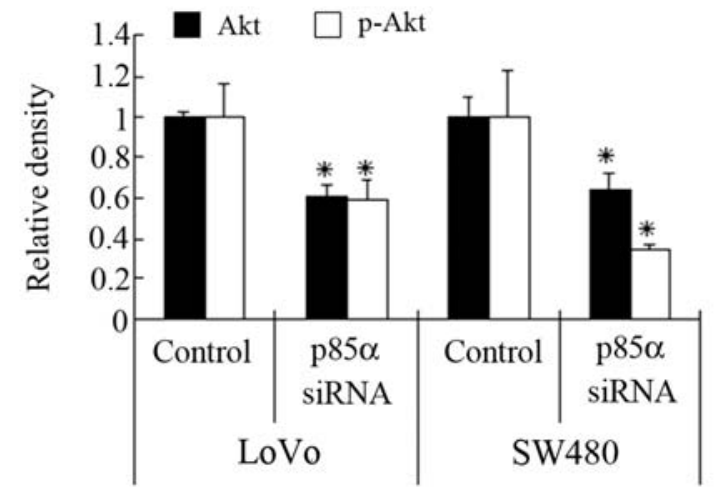

Figure 5. PI3K p85a knockdown inactivated Akt. (A) Following stable transfection, whole cell extracts were analyzed by Western blotting for Akt and p-Akt proteins. The corresponding B-actin levels were used as loading controls. (B) Quantification of immunoblot data from at least three experiments, the amount of each protein was calculated relative to $B$-actin and normalized to control cells. Columns, relative mean density; bars, $+\mathrm{SD}$. ${ }^{*} \mathrm{P}<0.05$, compared to those of control cells.

was simultaneously observed (Fig. 6A and B). Because the potential downstream targets of FoxO transcription factors are cell cycle-associated proteins and apoptosis-associated 
A

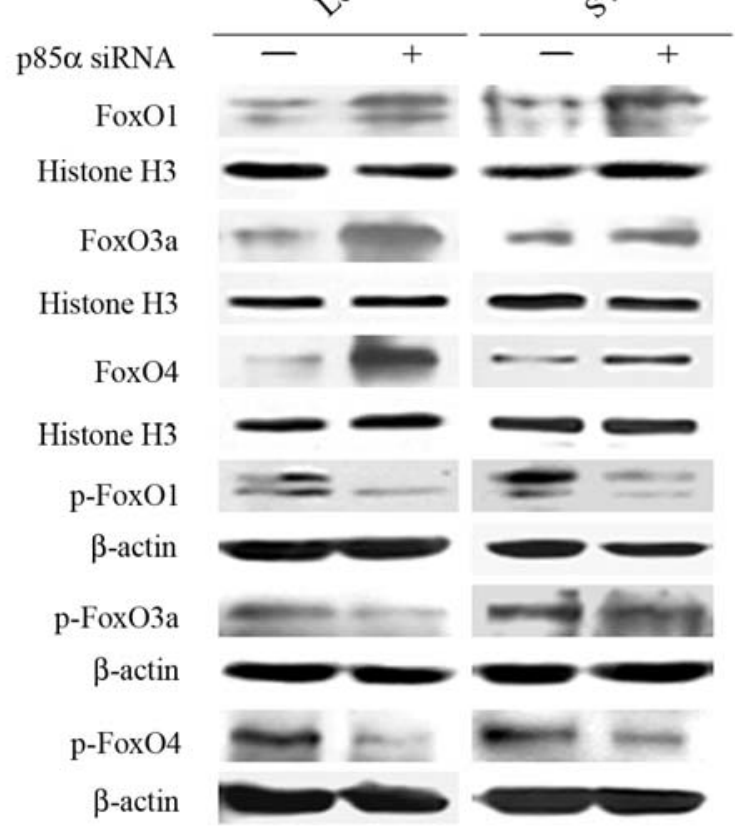

B $\square$ FoxO1 $\square$ FoxO3a $\square$ FoxO4

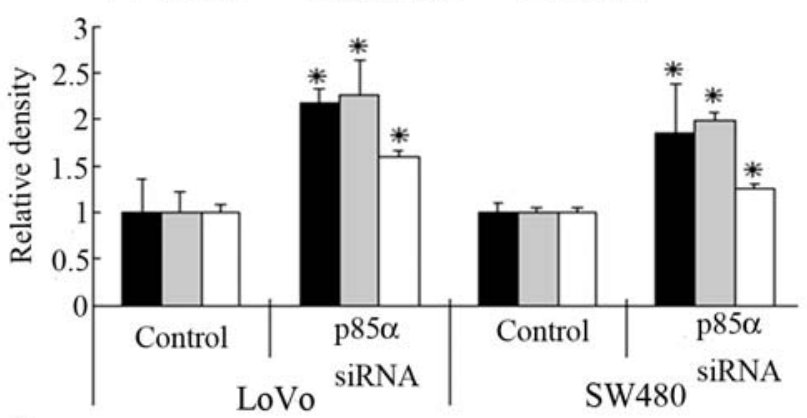

$\mathrm{C} \square$ p-FoxOl $\square$ p-FoxO3a $\square$ p-FoxO4

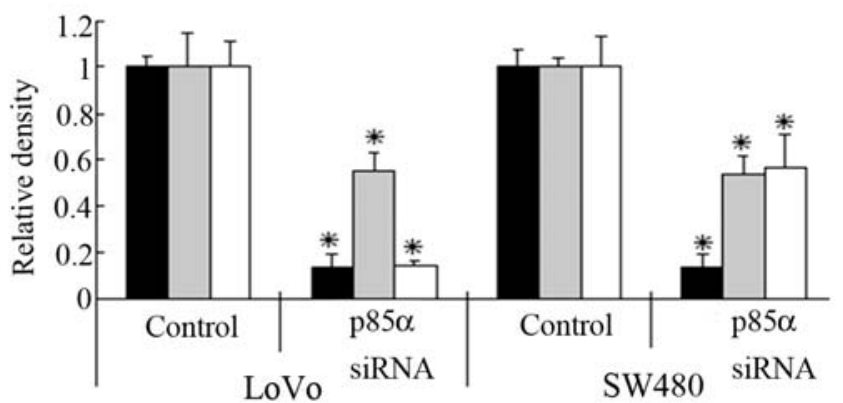

Figure 6. PI3K p85a knockdown activated FoxO transcription factors. (A) Following stable transfection, nuclear extracts and cytoplasmic extracts were analyzed by Western blots for FoxO proteins and phosphorylated FoxO proteins, respectively. The corresponding Histone $\mathrm{H} 3$ and $\mathrm{\beta}$-actin levels were used as loading controls. (B) Quantification of immunoblot data from at least three experiments, the amount of nuclear protein was calculated relative to Histone H3 and normalized to control cells, the amount of cytoplasmic protein was calculated relative to $\beta$-actin and normalized to control cells. Columns, relative mean density; bars, $+\mathrm{SD}$. ${ }^{*} \mathrm{P}<0.05$, compared to those of control cells.
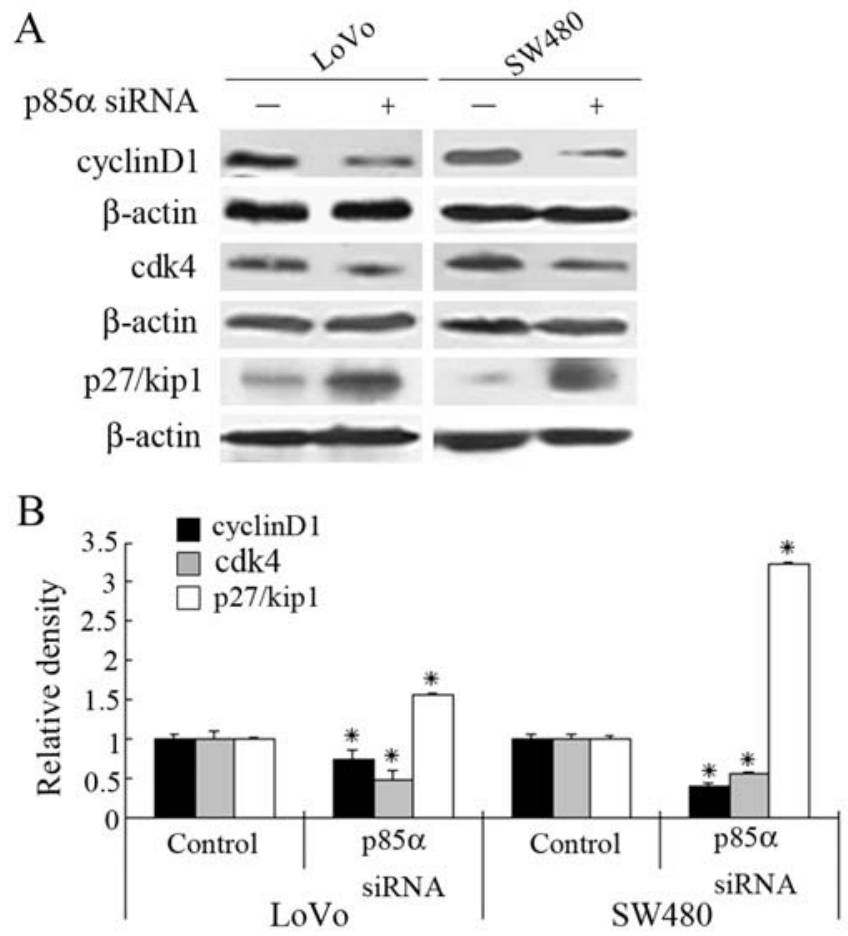

Figure 7. PI3K p $85 \alpha$ depletion led to a change in cell cycle regulatory proteins (A) Following stable transfection, whole cell extracts were analyzed by Western blotting for cyclin D1, cdk4 and p27/Kip1 proteins. The corresponding B-actin levels were used as loading controls. (B, C) Quantification of immunoblot data from at least three experiments, the amount of each protein was calculated relative to $\beta$-actin and normalized to control cells. Columns, relative mean density; bars, $+\mathrm{SD} .{ }^{*} \mathrm{P}<0.05$, compared to those of control cells.

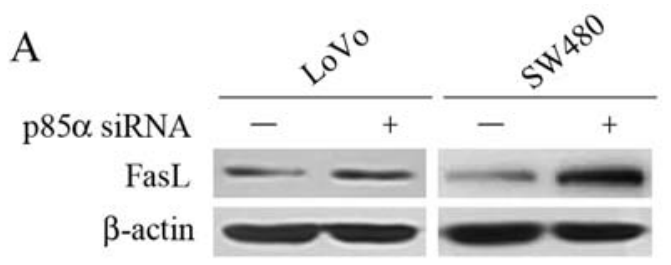

B

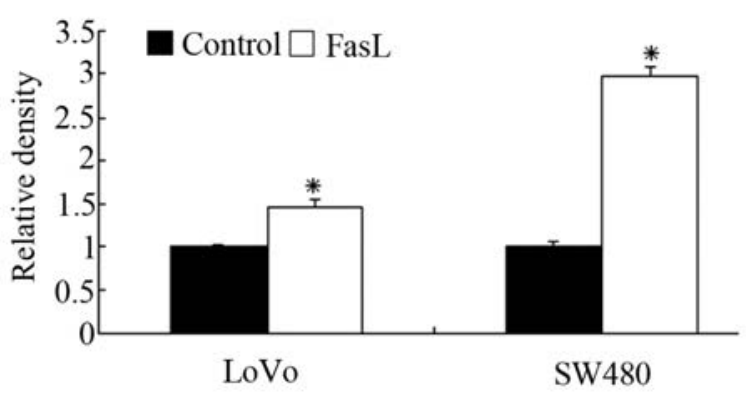

Figure 8. PI3K p85 $\alpha$ depletion increased expression level of FasL. (A) Following stable transfection, whole cell extracts were analyzed by Western blotting for FasL protein. The corresponding $\beta$-actin levels were used as loading controls. (B, C) Quantification of immunoblot data from at least three experiments, the amount of each protein was calculated relative to $\beta$-actin and normalized to control cells. Columns, relative mean density; bars, $+\mathrm{SD}$. ${ }^{*} \mathrm{P}<0.05$, compared to those of control cells.

proteins, the expression levels of cyclin D1, cdk4, p27/Kip1 and FasL were also determined. As shown in Fig. 7, the expression levels of cyclin D1 and cdk4 were significantly decreased in p85a depleted cells, while that of the cyclin 
kinase inhibitor p27/Kip1 and FasL (Fig. 8) were markedly increased.

\section{Discussion}

Aberrant activation of PI3K/Akt pathway components has been observed in many cancers. Akt is overexpressed in a number of cancers, including colon, pancreatic, ovarian, and some steroid hormone-insensitive breast cancers $(12,13)$. Loss of phosphatidylinositol 3-kinase and phosphatase and tensin homologue (PTEN) function, due to somatic deletions or mutations of this tumor suppressor gene, are frequently detected in many human cancers $(14,15)$. The gene coding for $\mathrm{p} 110 \alpha(P I K 3 C A)$ is amplified in ovarian and breast tumors (16), PIK3CA has somatic mutations in several other cancers, including $32 \%$ of colorectal cancers, $27 \%$ of glioblastomas, $25 \%$ of gastric cancers (17), implicating PIK3CA as a potential oncogene in these cancers. An oncogenic mutated form of PI3K p85 $\alpha$ has also been described (18). Recent studies have also shown that $\mathrm{p} 85 \alpha$ forms a complex with a protein network that is associated with oncogenic fusion tyrosine kinases (FTKs), resulting in constitutive activation of the p110 catalytic subunit of PI3K (19). Therefore, PI3K inhibitors could potentially provide useful information about the role of the PI3K/Akt pathway in human cancers. However, this pathway regulates a variety of cellular processes, some of which are necessary to maintain normal physiological functions. The most commonly used broad-spectrum PI3K inhibitors, LY294002 and wortmannin, may therefore potentially contribute to the undesirable side-effects.

Recent progress in the siRNA technique has demonstrated that it is an efficient method for silencing specific genes (20). For siRNA to be applied therapeutically, however, several problems need to be solved, including the delivery method and the short duration of siRNA-mediated silencing. Despite these problems, siRNA remains a potentially promising technique for the treatment of human cancer, especially given that it can be more selective and less toxic than traditional approaches. In our study, siRNA-mediated targeted depletion of PI3K p85a resulted in significant inhibition of PI3K p85a protein levels in LoVo and SW480 cells.

PI3K activation is required for cancer progression because it promotes tumor growth through cell proliferation and cell cycle progression (21). As shown in the CCK-8 assays, we observed a significant decrease in cell proliferation in both colorectal carcinoma cell lines after treatment with $\mathrm{p} 85 \alpha$ siRNA, which demonstrated that inhibition of PI3K p85 can affect tumor cell growth. Given that another cause of tumorigenesis is uncontrolled cell division, we also wanted to prove that $\mathrm{p} 85 \alpha$ inhibition could affect cell proliferation through cell cycle regulation. Flow cytometry analyses showed that depletion of $\mathrm{p} 85 \alpha$ resulted in a significant increase in the accumulation of LoVo and SW480 cells in the G1 phase of the cell cycle. The observed increase in the number of colorectal carcinoma cells that were in the G1 was accompanied by a reduction in the number of cancer cells in $\mathrm{S}$ phase. These results are consistent with observations in breast carcinoma cells and consistent with studies that involved the treatment of breast carcinoma BT-474 and osteosarcoma Saos-2 cells with PI3K inhibitor LY294002 (22-24).
One important function of activated PI3K in cells is inhibition of apoptosis. PI3K inhibition may be associated with an induction of apoptosis in cancer cells $(25,26)$. Given that $5-\mathrm{FU}$ is one of the most widely used agents in colorectal cancer chemotherapy, we used the Annexin V-FITC kit to determine the effect of p $85 \alpha$ knockdown on 5-FU-induced apoptosis. Our data show that the proportion of cells that were positive for Annexin $\mathrm{V}$ was about 7-fold higher in p85a knockdown cells than in the control cells. The results indicate that the down-regulation of the PI3K/Akt pathway by PI3K p $85 \alpha$ RNAi play a role in the sensitivity of colorectal cancer cells to 5-FU treatment. Our study suggested that the combination of 5-FU treatment and PI3K p85 $\alpha$ depletion might be a potential strategy for cancer chemotherapy.

Studies have suggested that FoxO transcription factors, which belong to the Forkhead family of proteins, are controlled by PI3K/Akt signaling and involved in regulating cell cycle progression and cell death (27). Direct phosphorylation by Akt inhibits transcriptional activation of FoxO factors, which results in their displacement from the nucleus into the cytoplasm. In the absence of Akt activity, FoxO transcription factors are predominantly nuclear and are presumed to be active, inducing either cell cycle arrest or apoptosis via transcriptional modulation of a variety of genes (28). In order to further explore the mechanism that may be involved in the enhanced cell cycle arrest and 5-FU-induced apoptosis by p $85 \alpha$ silencing in colorectal cells, we determined the effect of p85a knockdown on the regulation of FoxO transcription factors. We first evaluated the effect of $\mathrm{p} 85 \alpha$ depletion on Akt activation, which directly phosphorylates and represses the FoxO transcription factors. As shown by Western blot analyses, p85 $\alpha$ depletion led to a substantial reduction in the levels of Akt and phospho-Akt, indicating that treatment with p85a siRNA is similar to direct inhibition of Akt activation. In the following Western blot analyses, we found that targeted siRNA depletion of p85 $\alpha$ in colorectal carcinoma cells resulted in a significant increase in nuclear FoxO1, FoxO3a and FoxO4 proteins. Our data also show that $\mathrm{p} 85 \alpha$ depletion resulted in a significant decrease in the phosphorylated forms of FoxO1, FoxO3a and FoxO4 in the cytosol. These observations provide strong evidence that inhibition of PI3K p85 $\alpha$ activated FoxO transcription factors in both LoVo and SW480 cells.

All three Forkhead protein families have been reported to inhibit cell cycle progression at the G1/S transition (29). Consequently, we studied a series of proteins that are related to G1/S cell cycle transition and transcriptionally regulated by activation of FoxO transcription factors. Western blot analyses showed that the expression levels of cyclin D1 and cdk4 were significantly decreased in $\mathrm{p} 85 \alpha$ knockdown cells, while the expression levels of cyclin kinase inhibitor p27/ Kip1 were markedly induced. These results are consistent with the findings obtained from ER $\alpha$-positive breast carcinoma cells (22). Recent reports have indicated that upregulation of some pro-apoptotic genes are likely correlated with FoxO nuclear localization $(28,30)$. Reports on FoxO target genes that could be responsible for the induction of cell death in colorectal cancer cells are rare. In the present study, expression level of FasL protein was significantly increased in p85a knockdown cells, which may be involved 
in the enhanced sensitivity to 5-FU-induced apoptosis in p85 $\alpha$ depletion cells

In summary, our results demonstrate that targeted silencing of PI3K p $85 \alpha$ by RNA interference in human colorectal cancer cells inhibited cell proliferation, induced G1 phase cell cycle arrest, and sensitized colorectal cancer cells to 5-FU-induced apoptosis. The mechanism that may be involved in these observations was an activation of FoxO transcription factors, which, in turn, activated transcription of certain target genes, such as those involved in cell cycle regulation and apoptosis. The present study suggests that development of gene therapeutic approaches or pharmacologic inhibitors directed at PI3K p $85 \alpha$ may be a feasible method for the management of colorectal cancer.

\section{Acknowledgements}

This study was supported by National Natural Science Foundation of China (30300159).

\section{References}

1. Mano MS and Duhoux F: Colon cancer: update on adjuvant therapy. Clin Colorectal Cancer 7: 178-183, 2008.

2. Hamilton SR: Targeted therapy of cancer: new roles for pathologists in colorectal cancer. Mod Pathol 21: S23-S30, 2008.

3. Fruman DA, Meyers RE and Cantley LC: Phosphoinositide kinases. Annu Rev Biochem 67: 481-507, 1998.

4. Yu J, Zhang Y, McIlroy J, Rordorf-Nikolic T, Orr GA and Backer JM: Regulation of the p85/p110 phosphatidylinositol 3'-kinase: stabilization and inhibition of the p110alpha catalytic subunit by the p85 regulatory subunit. Mol Cell Biol 18: 1379-1387, 1998.

5. Rychahou PG, Murillo CA and Evers BM: Targeted RNA interference of PI3K pathway components sensitizes colon cancer cells to TNF-related apoptosis-inducing ligand (TRAIL). Surgery 138: 391-397, 2005.

6. Osaki M, Oshimura M and Ito H: PI3K-Akt pathway: its functions and alterations in human cancer. Apoptosis 9: 667-676, 2004.

7. Blume-Jensen $\mathrm{P}$ and Hunter T: Oncogenic kinase signalling. Nature 411: 355-365, 2001

8. Phillips WA, St Clair F, Munday AD, Thomas RJ and Mitchell CA: Increased levels of phosphatidylinositol 3-kinase activity in colorectal tumors. Cancer 83: 41-47, 1998.

9. Khaleghpour K, Li Y, Banville D, Yu Z and Shen SH Involvement of the PI 3-kinase signaling pathway in progression of colon adenocarcinoma. Carcinogenesis 25: 241-248, 2004.

10. Shao J, Evers BM and Sheng H: Roles of phosphatidylinositol 3'-kinase and mammalian target of rapamycin/p70 ribosomal protein S6 kinase in K-Ras-mediated transformation of intestinal epithelial cells. Cancer Res 64: 229-235, 2004.

11. Sun Y, Tian H, Xiao FM, Xie XY and Song YG: The expression and significance of PI3K p85 $\alpha$ in colorectal cancer. J First Mil Med Univ 29: 416-418, 2009.

12. Qiu W, Schönleben F, Li X, Ho DJ, Close LG, Manolidis S, Bennett BP and Su GH: PIK3CA mutations in head and neck squamous cell carcinoma. Clin Cancer Res 12: 1441-1446, 2006.

13. Kawano O, Sasaki H, Endo K, Suzuki E, Haneda H, Yukiue H, Kobayashi Y, Yano M and Fujii Y: PIK3CA mutation status in Japanese lung cancer patients. Lung Cancer 54: 209-215, 2006.
14. Yokomizo A, Tindall DJ, Hartmann L, Jenkins RB, Smith DI and Liu W: Mutation analysis of the putative tumor suppressor PTEN/MMAC1 in human ovarian cancer. Int J Oncol 13: 101-105, 1998.

15. Saito M, Okamoto A, Kohno T, Takakura S, Shinozaki H, Isonishi S, Yasuhara T, Yoshimura T, Ohtake Y, Ochiai K, Yokota J and Tanaka T: Allelic imbalance and mutations of the PTEN gene in ovarian cancer. Int J Cancer 85: 160-165, 2000.

16. Campbell IG, Russell SE, Choong DY, Montgomery KG, Ciavarella ML, Hooi CS, Cristiano BE, Pearson RB and Phillips WA: Mutation of the PIK3CA gene in ovarian and breast cancer. Cancer Res 64: 7678-7681, 2004.

17. Samuels Y, Wang Z, Bardelli A, Silliman N, Ptak J, Szabo S, Yan H, Gazdar A, Powell SM, Riggins GJ, Willson JK, Markowitz S, Kinzler KW, Vogelstein B and Velculescu VE: High frequency of mutations of the PIK3CA gene in human cancers. Science 304: 554, 2004

18. Jimenez C, Jones DR, Rodríguez-Viciana P, Gonzalez-García A, Leonardo E, Wennström S, von Kobbe C, Toran JL, R-Borlado L, Calvo V, Copin SG, Albar JP, Gaspar ML, Diez E, Marcos MA, Downward J, Martinez-A C, Mérida I and Carrera AC: Identification and characterization of a new oncogene derived from the regulatory subunit of phosphoinositide 3-kinase. EMBO J 17: 743-753, 1998

19. Ren SY, Bolton E, Mohi MG, Morrione A, Neel BG and Skorski T: Phosphatidylinositol 3-kinase p85\{alpha\} subunitdependent interaction with BCR/ABL-related fusion tyrosine kinases: molecular mechanisms and biological consequences. Mol Cell Biol 25: 8001-8008, 2005.

20. Takeshita $F$ and Ochiya T: Therapeutic potential of RNA interference against cancer. Cancer Sci 97: 689-696, 2006.

21. Fresno Vara JA, Casado E, De Castro J, Cejas P, Belda-Iniesta C and González-Barón M: PI3K/AKT signalling pathway and cancer. Cancer Treat Rev 30: 193-204, 2004.

22. Reagan-Shaw S and Ahmad N: RNA Interference-mediated depletion of phosphoinositide 3-kinase activates forkhead box class $\mathrm{O}$ transcription factors and induces cell cycle arrest and apoptosis in breast carcinoma cells. Cancer Res 66: 1062-1069, 2006.

23. Lenferink AE, Busse D, Flanagan WM, Yakes FM and Arteaga CL: ErbB2/neu kinase modulates cellular p27(Kip1) and cyclin D1 through multiple signaling pathways. Cancer Res 61: 6583-6591, 2001.

24. Ren S, Gao C, Zhang L, Koike K and Tsuchida N: PI3K inhibitors changed the p53-induced response of Saos-2 cells from growth arrest to apoptosis. Biochem Biophys Res Commun 308: 120-125, 2003.

25. Bondar VM, Sweeney-Gotsch B, Andreeff M, Mills GB and McConkey DJ: Inhibition of the phosphatidylinositol 3'-kinaseAKT pathway induces apoptosis in pancreatic carcinoma cells in vitro and in vivo. Mol Cancer Ther 12: 989-997, 2002.

26. Kim S, Kang J, Qiao J, Thomas RP, Evers BM and Chung DH: Phosphatidylinositol 3-kinase inhibition down-regulates survivin and facilitates TRAIL-mediated apoptosis in neuroblastomas. J Pediatr Surg 39: 516-521, 2004.

27. Kops GJ, De Ruiter ND, De Vries-Smits AM, Powell DR, Bos JL and Burgering BM: Direct control of the Forkhead transcription factor AFX by protein kinase B. Nature 398: 630-634, 1999.

28. Birkenkamp KU and Coffer PJ: Regulation of cell survival and proliferation by the FOXO (Forkhead box, class O) subfamily of Forkhead transcription factors. Biochem Soc Trans 31: 292-297, 2003.

29. Nakamura N, Ramaswamy S, Vazquez F, Signoretti S, Loda M and WR Sellers: Forkhead transcription factors are critical effectors of cell death and cell cycle arrest downstream of PTEN. Mol Cell Biol 20: 8969-8982, 2000.

30. Modur V, Nagarajan R, Evers BM and Milbrandt J: FOXO proteins regulate tumor necrosis factor-related apoptosis inducing ligand expression. Implications for PTEN mutation in prostate cancer. J Biol Chem 277: 47928-47937, 2002. 